\title{
Internal structures and high-velocity frictional properties of a bedding-parallel carbonate fault at Xiaojiaqiao outcrop activated by the 2008 Wenchuan earthquake*
}

\author{
Linfeng Hou ${ }^{1, \star} \quad$ Shengli Ma ${ }^{1} \quad$ Toshihiko Shimamoto ${ }^{1} \quad$ Jianye Chen ${ }^{1}$ \\ Lu Yao ${ }^{1}$ Xiaosong Yang ${ }^{1}$ and Yuji Okimura ${ }^{2}$ \\ ${ }^{1}$ State Key Laboratory of Earthquake Dynamics, Institute of Geology, China Earthquake Administration, \\ Beijing 100029, China \\ 2 Hiroshima University Museum, 1-1-1 Kagamiyama, Higashi-Hiroshima 739-8524, Japan
}

\begin{abstract}
This paper reports internal structures of a bedding-parallel fault in Permian limestone at Xiaojiaqiao outcrop that was moved by about $0.5 \mathrm{~m}$ during the $2008 M_{\mathrm{W}} 7.9$ Wenchuan earthquake. The fault is located about $3 \mathrm{~km}$ to the south from the middle part of Yingxiu-Beichuan fault, a major fault in the Longmenshan fault system that was moved during the earthquake. The outcrop is also located at Anxian transfer zone between the northern and central segments of Yingxiu-Beichuan fault where fault system is complex. Thus the fault is an example of subsidiary faults activated by Wenchuan earthquake. The fault has a strike of $243^{\circ}$ or $\mathrm{N} 63^{\circ} \mathrm{E}$ and a dip of $38^{\circ} \mathrm{NW}$ and is nearly optimally oriented for thrust motion, in contrast to high-angle coseismic faults at most places. Surface outcrop and two shallow drilling studies reveal that the fault zone is several centimeters wide at most and that the coseismic slip zone during Wenchuan earthquake is about $1 \mathrm{~mm}$ thick. Fault zone contains foliated cataclasite, fault breccia, black gouge and yellowish gouge. Many clasts of foliated cataclasite and black gouge contained in fault breccia indicate multiple slip events along this fault. But fossils on both sides of fault do not indicate clear age difference and overall displacement along this fault should not be large. We also report results from high-velocity friction experiments conducted on yellowish gouge from the fault zone using a rotary shear low to high-velocity frictional testing apparatus. Dry experiments at normal stresses of 0.4 to $1.8 \mathrm{MPa}$ and at slip rates of 0.08 to $1.35 \mathrm{~m} / \mathrm{s}$ reveal dramatic slip weakening from the peak friction coefficient of around 0.6 to very low steady-state friction coefficient of 0.1-0.2. Slip weakening parameters of this carbonate fault zone are similar to those of clayey fault gouge from Yingxiu-Beichuan fault at Hongkou outcrop and from Pingxi fault zone. Our experimental result will provide a condition for triggering movement of subsidiary faults or off-fault damage during a large earthquake.
\end{abstract}

Key words: Wenchuan earthquake; Longmenshan fault system; carbonate fault rock; high velocity friction; dynamic weakening of fault

CLC number: P315.2 Document code: A

\section{Introduction}

Two major surface ruptures formed during the

\footnotetext{
* Received 24 April 2012; accepted in revised form 27 May 2012; published 10 June 2012

+ Corresponding author. e-mail: houlinfeng1988@163.com

(C) The Seismological Society of China, Institute of Geophysics, China Earthquake Administration, and Springer-Verlag Berlin Heidelberg 2012
}

$2008 M_{\mathrm{W}} 7.9$ Wenchuan earthquake, Sichuan Province, China; one along the Yingxiu-Beichuan fault for over $250 \mathrm{~km}$ long and the other along the Hanwang fault (or Pengguan fault) for about $70 \mathrm{~km}$ in length (see inset map in Figure 1, quoted from Xu et al., 2009; see also Lin et al., 2009; Liu-Zeng et al., 2009; Li et al., 2010a; Fu et al., 2011). The maximum co-seismic displacement is $10 \pm 0.5 \mathrm{~m}$ recognized at a place north- 
east of Beichuan (Li et al., 2010a; Fu et al., 2011). Chinese government started the Wenchuan Earthquake Fault Scientific Drilling (WFSD) Project soon after the earthquake for better understanding of the mechanisms of this disastrous earthquake, and four deep drilling into the two coseismic faults are being conducted now (e.g., $\mathrm{Xu}$ and Li, 2010; Li et al., 2010b). Moreover, Institute of Geology, China Earthquake Administration (CEA), has started an integrated fault and earthquake project, trying to reproduce Wenchuan earthquake based on measured fault-zone properties (Han et al., 2010; Chen et al., 2011; Yang et al., 2012). The purposes of the latter project are (1) to study deformation processes in fault zones constituting the Longmenshan fault system at the boundary of Tibetan plateau and Sichuan basin, and (2) to reproduce intrafault processes in laboratory experiments and determine mechanical and transport properties of faults. By working on fault zones at surface outcrops and on shallow drill cores, it is hoped to get information on along-fault and depth variation of the internal structures and mechanical/transport properties of fault zones. Results from such studies will be used eventually to reproduce the Wenchuan earthquake by modeling using measured properties. The present work was done as a part of the project at Institute of Geology, CEA.

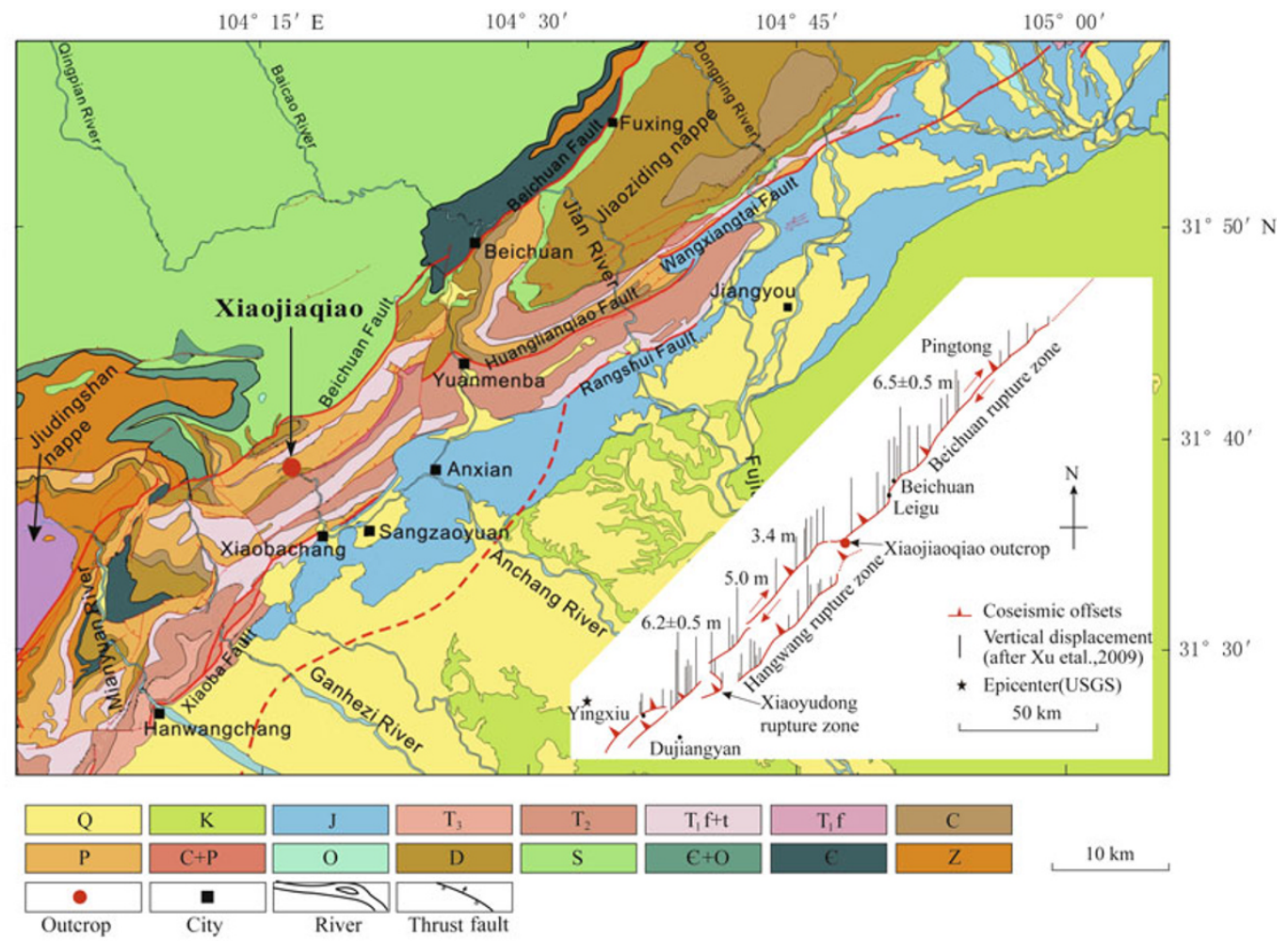

Figure 1 Location and geological setting of Xiaojiaqiao outcrop, plotted on a geological map of the Anxian transfer zone after Jin et al. (2010; their Figure 7 without cross-sectional lines are used here). Red solid lines are coseismic surface ruptures associated with the 2008 Wenchuan earthquake. Xiaojiaqiao outcrop (shown by a red circle) is located along Anchang river and its GPS locations is $104^{\circ} 16^{\prime} 50^{\prime \prime} \mathrm{E}$ and $31^{\circ} 38^{\prime} 51^{\prime \prime} \mathrm{N}$ (the plotted outcrop location was determined from topography, not from GPS location). The inset map shows the surface rupture map with distribution of coseismic vertical displacement after Xu et al. (2009) and the location of Xiaojiaqiao outcrop in red circle. Notations of the symbols in the index are Q: Quaternary, K: Cretaceous, J: Jurassic, T: Triassic, C: Carboniferous, P: Permian, O: Ordovician, D: Devonian, S: Silurian, $\in$ : Cambrian and Z: Sinian or Ediacaran (Neoproterozoic) (see Jin et al. (2010) for more details).

Jin et al. (2010) divided the Longmenshan thrust belt into three segments and two transfer zones based on field investigations and interpretations of seismic pro- files. We studied a small-scale bedding-parallel fault in Permian limestone at Xiaojiaqiao outcrop, located at Anxian transfer zone between the northern and central 
segments of the thrust belt. Faults are less continuous and complex in the transfer zone (see Figure 1 in Jin et al., 2010). The outcrop is located about $3 \mathrm{~km}$ to the south of Yingxiu-Beichuan fault (red dot in Figure 1), so that the fault zone we studied is not a major coseismic fault that caused the Wenchuan earthquake. Chang et al. (2012) reported Xiaoyudong fault, about $90 \mathrm{~km}$ to the southwest from the present outcrop, as an example of activated faults during the Wenchuan earthquake. The main coseismic faults of the Wenchuan earthquake are mostly high-angle reverse faults dipping steeply $\left(60^{\circ}-80^{\circ}\right)$ to the northwest, with right-lateral strike-slip displacement increasing towards the northeast (e.g., Xu et al., 2008). But the fault at Xiaojiaqiao outcrop has a strike of $\mathrm{N} 63^{\circ} \mathrm{E}$ (similar to the strike of Yingxiu-Beichuan fault) and a dip of $38^{\circ} \mathrm{NW}$. Thus the fault is nearly optimally oriented for the thrust motion. Li et al. (2008) reported coseismic vertical displacement as large as $5 \mathrm{~m}$ at this outcrop, corresponding to a fault displacement of around $8 \mathrm{~m}$. However, we got witness from local residents that there was a cliff higher than $2 \mathrm{~m}$ prior to the Wenchuan earthquake. We reexamine the amount of coseismic displacement in this paper although this cannot be determined accurately because of the lack of clear displacement markers.

We report here internal structures of the beddingparallel fault at Xiaojiaqiao outcrop, their folded and faulted structures in the fault zone and structures within narrow incohesive fault zone along the main slip zone in particular. Evidences of multiple slip events along this fault were found in the fault rocks, but examination of fossils on both sides of the fault did not reveal important difference in age of the host rocks. We thus show that the fault at Xiaojiaqiao outcrop is an example of small-scale bedding parallel faults in limestone that was moved during the Wenchuan earthquake.

We also report results from high-velocity friction experiments of fault gouge from Xiaojiaqiao outcrop and on host-rock limestone, using a new rotary-shear low to high-velocity friction apparatus newly installed at Institute of Geology, China Earthquake Administration. The apparatus is capable of producing plate velocity on the order of several tens of $\mathrm{mm} / \mathrm{a}$ to seismic slip rates of around a few $\mathrm{m} / \mathrm{s}$, but we focus here on frictional properties at intermediate to high-velocities (or subseismic to seismic slip rates). Frictional properties at low slip rates such as those conducted by Verberne et al. (2010) on gouge from the Yingxiu-Beichuan fault gouge may control nucleation processes of an earthquake (e.g., Scholz, 2002). However, the fault we studied is away from the epicenter and is not the nucleation site, so that intermediate to high-velocity frictional properties (e.g., Rice, 2006) are important to evaluate the response of a fault to the earthquake rupture during an earthquake. We compare our results with those of Togo et al. (2011a) on the Yingxiu-Beichuan fault zone at Hongkou outcrop and of Yao et al. (2011) on the Pingxi fault zone. Subsidiary fault motion in host rock is a mechanism to dissipate energy of earthquake and this is a type of off-fault damage (Rice et al., 2005; Templeton and Rice, 2008). Our data will be useful for a criterion for the activation of fault slip in host rock.

\section{Internal structures of a bedding- parallel fault zone at Xiaojiaqiao outcrop}

\subsection{Geological setting and fault-zone struc- tures of the Xiaojiaqiao outcrop}

The Xiaojiaqiao outcrop is located along the Anchang river in Anxian transfer zone of Jin et al. (2010) with GPS locating of $104^{\circ} 16^{\prime} 51^{\prime \prime} \mathrm{E}$ and $31^{\circ} 38^{\prime} 51^{\prime \prime} \mathrm{N}$. But the GPS location cannot be spotted precisely on a geological map of 1: 200000 in scale used in our study. We thus carefully determined its location (red spot with "Xiaojiaqiao" in Figure 1) from topography by tracing from a branching river position along the Anchang River. The outcrop is within Permian limestone and about $3 \mathrm{~km}$ to the south from Yingxiu-Beichuan fault, which has coseismic vertical displacement of about $3.5 \mathrm{~m}$ near the outcrop (inset map of Figure 1). The age of limestone host rock is confirmed from fossils to be reported later.

Well-bedded limestone is exposed nearly perfectly over about $200 \mathrm{~m}$ in width with the maximum height of about $100 \mathrm{~m}$ at Xiaojiaqiao outcrop (see a whole view in a photograph in Figure 2a). Sketch map in Figure $2 \mathrm{~b}$ displays bedding plane by thin solid lines, the upper bound of a fault zone is represented by a dashed line on the left side, coseismic slip zone during the Wenchuan earthquake by a thick solid line going through near the electric tower, and small-scale faults in thin dashed lines. Thus the fault zone has a disturbed zone of about $40 \mathrm{~m}$ in width, characterized by gentle folds and smallscale faults. Small-scale faults shown as thin dashed lines were recognized as discontinuous surfaces across which orientation of bedding is discontinuous (see a close-up photograph and its sketch in Figures 3a and 3c). A typical structure is seen at the lower-right side of 
fault zone (a block above point D in Figure 3c) where limestone body is bounded by two faults curved concave upper-leftwards and bedding plane is folded gently concave lower-rightwards. It appears that the limestone body is overlapped with a similar body underneath it, forming a duplex-like structure (Figures $3 \mathrm{a}$ and $3 \mathrm{c}$ ). A fault zone at point $D$ consists of a few mm-thick fault gouge and a few to several cm-wide fault breccia zone (Figure 3d; coin for scale is $18 \mathrm{~mm}$ in diameter).
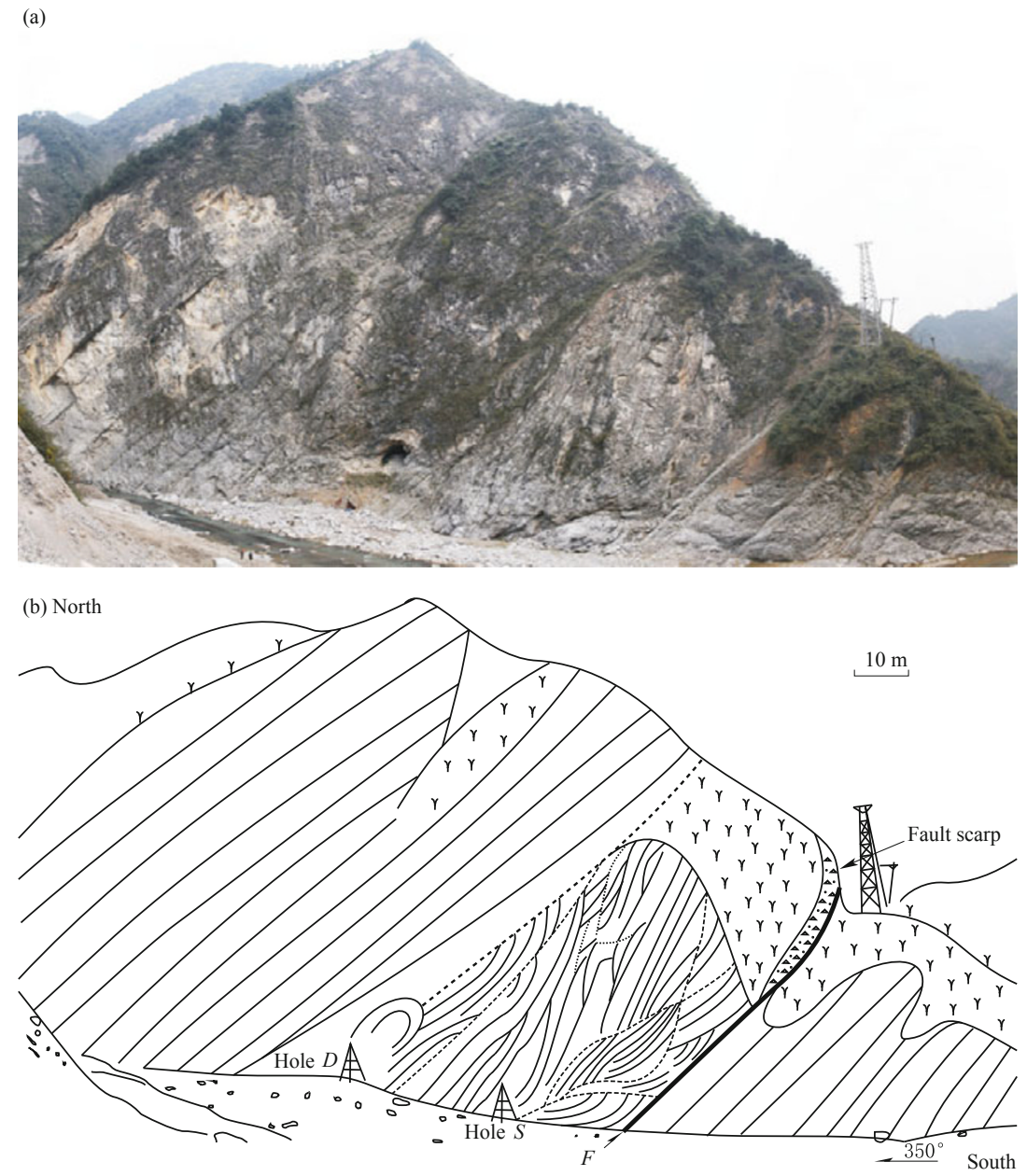

Figure 2 A photograph (a) and its sketch (b) of Xiaojiaqiao outcrop with Anchang river running in the front. Thick solid line $F$ shows the coseismic fault that moved during the 2008 Wenchuan earthquake. Dashed line on the left side line is the presumed northwestern boundary of fault zone across which the orientation of bedding planes is discontinuous. The coseismic fault has a strike of $243^{\circ}$ or $\mathrm{N} 63^{\circ} \mathrm{E}$ and a dip of $38^{\circ} \mathrm{NW}$ (the outcrop orientation is roughly $350^{\circ}$ or $\mathrm{N} 10^{\circ} \mathrm{W}$ ). Two vertical holes were drilled at Hole $D$ (85.9 m deep) and at Hole $S$ (21.6 m deep).

On the other hand, coseismic slip during the Wenchuan earthquake occurred parallel to a very flat surface $A, B$ and $C$ in Figure $3 \mathrm{~b}$; the photograph was taken upward from the bottom of coseismic fault near $F$ in Figure 2b. Measured strikes and dips of the fault are $244^{\circ}$ or $\mathrm{N} 64^{\circ} \mathrm{E}$ and $42^{\circ} \mathrm{NW}, 240^{\circ}$ or $\mathrm{N} 60^{\circ} \mathrm{E}$ and $38^{\circ} \mathrm{NW}$, and $245^{\circ}$ or $\mathrm{N} 65^{\circ} \mathrm{E}$ and $36^{\circ} \mathrm{NW}$, respectively. Thus we take $243^{\circ}$ or $\mathrm{N} 63^{\circ} \mathrm{E}$ and a dip of $38^{\circ} \mathrm{NW}$ as the representative orientation of the fault. Locally developed striation on the fault is nearly parallel to the dip and the coseismic fault motion was a reverse fault motion. Limestone below the coseismic zone has very flat bedding plane (Figures 2, 3a and 3c) and hence the coseismic slip zone occurred at the lower bound of the fault zone.

A few to several centimeter-wide fault gouge and 
breccia zone is recognized along the coseismic slip zone (Figure 3e), but the incohesive fault zone varies in thickness and is nearly absent locally. However, about $1 \mathrm{~mm}$ thick gouge zone mostly with yellowish color is developed continuously along the footwall side of the fault zone adjacent to the planar bedding plane of hostrock limestone (Figure 3f). This thin gouge formed even where incohesive fault zone is almost missing. We did not recognize internal structures within this gouge. Thus the thin gouge zone is likely to have been formed during the Wenchuan earthquake. Han et al. (2010) also considered that the thin gouge zone formed during the Wenchuan earthquake.


Figure 3 (a) A close-up photograph of the lower part of fault zone; (b) a photograph of very planar surface of the main fault extending from $A, B$ to $C$; (c) a sketch of (a) with solid and dashed lines showing deformed bedding layers and small scale faults developed within the fault zone, respectively; (d) a photograph of small-scale fault zone at a position $D$ in (c); (e) a photograph of the fault zone along the main fault at a position $E$ in (c); (f) a close-up photograph showing the fault gouge (ca. $1 \mathrm{~mm}$ thick) constituting the coseismic slipping zone collected at around point $F$ in (e). The color of fault gouge in incohesive fault zone in (e) is yellow with brownish tone when it is moist. But the gouge looks more yellow when it is dry and we call it "yellowish gouge" in this paper. 


\subsection{Coseismic displacement during the Wenchuan earthquake}

There is a cliff higher than $5 \mathrm{~m}$ on the other side of ridge viewed up from the fault in Figure $3 \mathrm{~b}$. We show a photograph in Figure 4a, taken in the direction of an arrow with (a) in Figure 4b. Li et al. (2008) surveyed this outcrop soon after the Wenchuan earthquake and proposed that the maximum vertical displacement was $5.4 \mathrm{~m}$. In view of the dip angle of the fault $\left(38^{\circ}\right)$, this corresponds to fault displacement over $8 \mathrm{~m}$ which is too large even for the Yingxiu-Beichuan fault near the outcrop. We got information from local residents (Zishou Chen and his friend) on April 11, 2012 that there had been a cliff higher than $2 \mathrm{~m}$ prior to the Wenchuan earthquake. Thus it is unlikely that the entire cliff formed during the earthquake, contrary to the assumption by Li et al. (2008). Another local resident witnessed that the cliff formed at the time of the 2008 Wenchuan earthquake and has not changed ever since. Thus there is no doubt the fault at this outcrop moved during the main shock, not during an aftershock.


(d)

Figure 4 (a) A photograph of fault scarp of coseismic fault at ridge of mountain; (b) a wide view of the fault scarp taken from the south; (c) a close-up of fault scarp $A$ to $B$ (see the same symbols in (b) for reference points); (d) schematic diagram showing the relationship of coseismic fault $F$, mountain slope and a possible coseismic displacement during Wenchuan earthquake. Arrows with (a) and (c) in photograph (b) indicates the position and orientations for taking photographs (a) and (c), respectively.

We also recognized that a topography similar to fault scarp still remains from point $A$ to $B$ in Figure $4 \mathrm{~b}$, and further to the right (eastwards) for about 100 $\mathrm{m}$. The length of the fault scarp is $1.5 \mathrm{~m}$ at a point between $A$ and $B$ in Figures $4 \mathrm{~b}$ and 4c. Figure 4d exhibits geometrical relationship among fault with reverse displacement, possible fault scarp and the present mountain slope. Fault displacement cannot be determined unless the initial slope of fault scarp portion is known. However, the displacement along the fault is estimated to be about $0.5 \mathrm{~m}$ if it is assumed that the slope have been the same as the upper portion of the slope $\left(45^{\circ}\right)$ and that the triangular portion shown by dashed lines in Figure 4d have collapsed after the earthquake to form the present scarp. We are not confirmed about how accurate this estimate is, but it will give a rough order estimate of the coseismic fault displacement at this outcrop, which is much smaller than the initial estimate by Li et al. (2008). The magnitude of an earthquake caused by a fault displacement of $0.5 \mathrm{~m}$ would be around 6.5, using an empirical relationship between the earthquake magnitude and the maximum coseismic displacement, compiled by Wells and Coppersmith (1994) for earthquakes accompanied by surface ruptures in the world. 




Figure 5 Composite photographs of drill cores from hole $D$ (a) and those from hole $S$ (b). (c) A schematic diagram showing the relationship between the main slip zone $F$ and holes $D$ and $S$. Close-up photographs of drill cores were stitched to make (a) and (b), with numbers on top and bottom showing the depths of cores and with the white portions indicating the depth intervals where cores could not be recovered. The dotted interval with no core, marked by 'FZ', is within an expected depth of fault judging from its dip angle. 'BL', 'CT' and 'FG' indicate locations for bedded limestone, for cataclasite and for fault gouge, respectively. D02 to D16 and S01 to S14 are samples for microscopic observations with their arrow points showing the sampling locations (arrows are not given for densely spaced samples).

\subsection{Fossils in shallow drill cores and surface outcrops}

Two shallow bore holes were drilled to study the fault zone at Xiaojiaqiao outcrop, hole $D$ down to 85.9 $\mathrm{m}$ and hole $S$ down to $21.6 \mathrm{~m}$ (see Figure 2b for their locations). Close-up photographs were stitched to make composite photographs of hole $D$ and hole $\mathrm{S}$ cores in Figures $5 \mathrm{a}$ and $5 \mathrm{~b}$, respectively (numbers on top and bottom of each column give the upper and lower depths of the column). Most cores were split into many thin disks and core recovery is not good as shown by the white portions for the depths of no core recovery. However, core photographs in Figure 5 are enlarged in horizontal direction (normal to the core) by 3.3 times to fit them in a figure. Thus shapes of broken pieces of rocks have to be recovered by making axial scale 3.3 
times larger than those in the photographs. Figure $5 \mathrm{c}$ exhibits a schematic relationship between the two drill cores and the coseismic fault denoted by $F$. The location of fault in hole $S$ was confirmed by the recovery of yellowish fault gouge (FG in Figure $5 \mathrm{~b}$ and a close-up photograph in Figure 6d). But hole $D$ cores were not recovered for an interval of about $5 \mathrm{~m}$ (43.5 to $48.5 \mathrm{~m}$ in depth) and it is likely that the fault goes through this depth interval (Figure 5c).

Sample observations and microscopic observations of thirty thin sections reveal that most core samples are undeformed host rock limestone and we did not give fault-rock classifications to the cores. Sample numbers and their locations are shown by D02-D16 and S01-S14 and by arrows in Figures 5a and 5b, respectively. Confirmed depths of fault gouge and cataclasite are shown by FG and $\mathrm{CT}$ in the figures, respectively. Examples of light-colored and dark-colored limestone are shown in photographs in Figures 6a and 6b (see caption for sample numbers and core depths). Host rock limestone is nearly undeformed and structureless like those examples. However, bedded limestone, typically several to a few tens of centimeters in thickness, is intercalated at places marked by "BL" in Figures 5a and 5b; see an example of bedded limestone in Figure 6c with bedding plane in upper-right to lower-left orientation. Small pieces of cataclasite such as the one in Figure 6e were found at three places in the cores (CT in Figures 5a and 5b). Cataclasite is a cohesive fault rock as hard as the host rock limestone. It is small scale and we could not recognize cataclasite as distinctive zones. Numerous calcite veins formed throughout the fault zone, but are particularly abundant near the coseismic slip zone (e.g., Figure 6f).
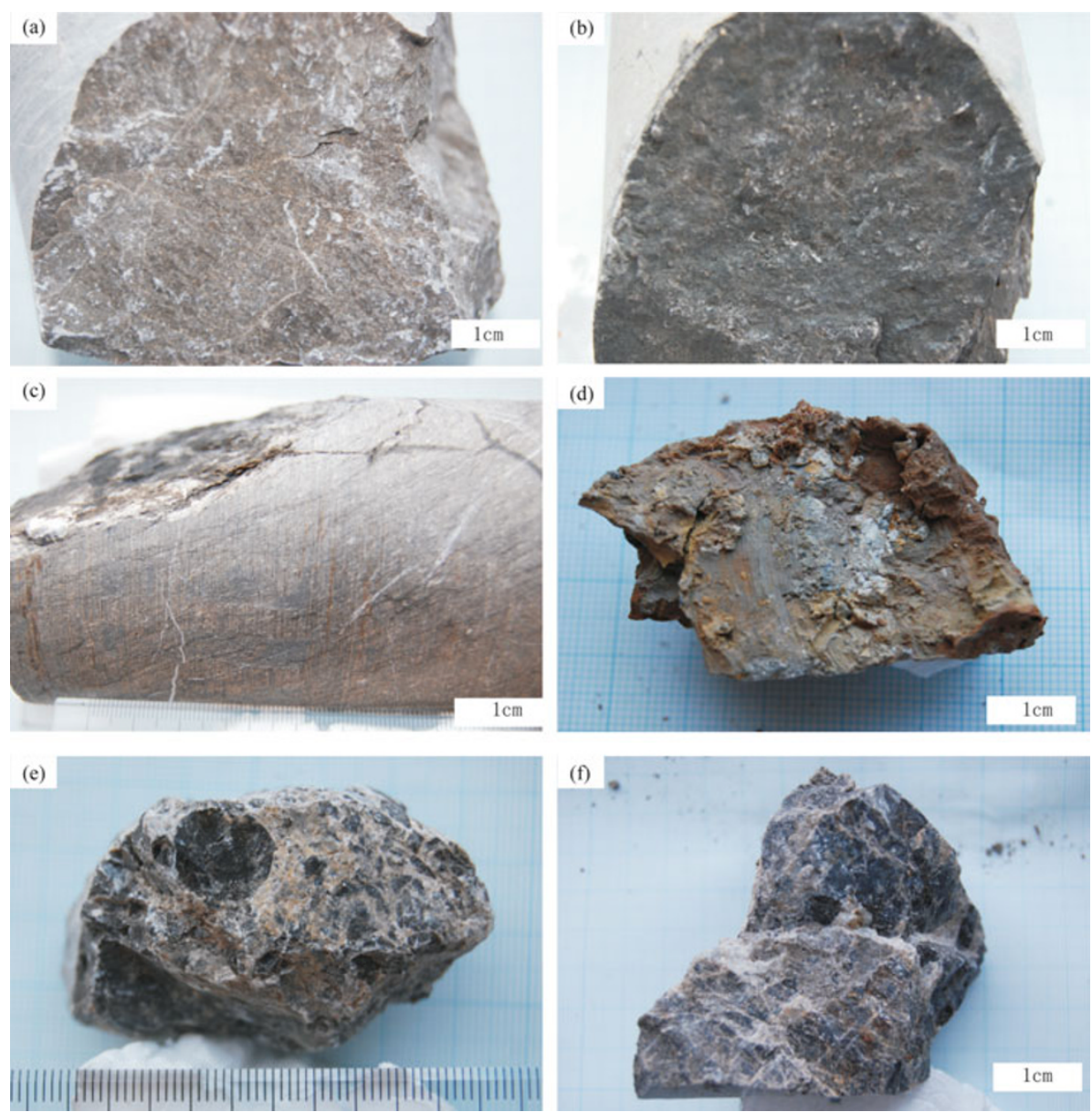

Figure 6 Photographs of core samples from drilling holes. (a) Light-colored limestone from hole D (sample D13 from $17.1 \mathrm{~m}$ depth); (b) dark-colored limestone from hole $D$ (sample D14 from $31.3 \mathrm{~m}$ depth); (c) bedded limestone from hole $D$ (37.6 m depth); (d) recovered yellowish gouge from hole $S$ (19.6 m depth); (e) cataclasite from hole $S$ (sample S11 from $18.5 \mathrm{~m}$ depth); (f) limestone with calcite veins (white portion) from hole $S$ (16.5 m depth). 

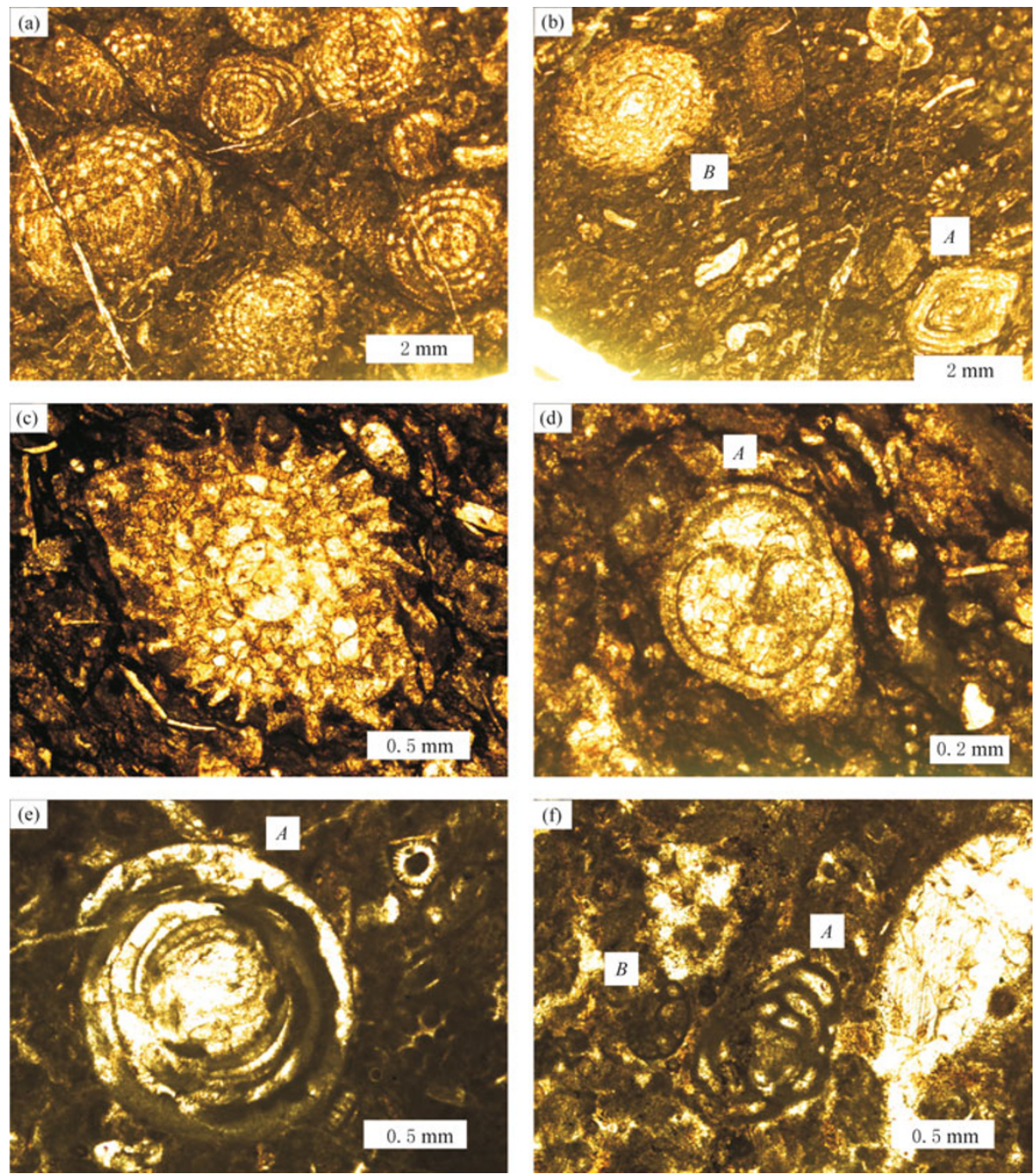

Figure 7 Microphotographs of fossils in the core samples. (a) Nankinella sp. (mostly in oblique section) from sample D07 (42.95 m depth); (b) A: Nankinella sp. (axial section) and B: Nankinella sp. (oblique section) from Sample D06 (36.4 m depth); (c) Staffella sp. from sample S01 (11.9 m depth); (d) A: Globivalvulina sp. (oblique section) from sample S07 (13.8 m depth); (e) A: Hemiogordiopsis sp. (horizontal axial section) from sample D15 (57.1 m depth), and (f) A: Agathammina sp. (vertical axial section) and B: Globivalvulina sp. (oblique section) from Sample D15 (57.1 m depth). Photomicrographs (a) to (d) and (e) and (f) were taken under plane and crossed polarized light, respectively.

Fossils are abundant in host rock limestone and we show photomicrographs of representative fossils that are useful for age determination, in Figure 7 (for identifications and ages of the fossils, see Loeblich and Tappan, 1964; Rauser-Chernoussova and Fursenko, 1962). The most abundant fossil is Nankinella sp. shown in Figure $7 \mathrm{a}$ in oblique sections and in Figure $7 \mathrm{~b}$ in both axial and oblique sections. Other confirmed fossils are Staffella sp. in Figure 7c, Globivalvulina sp. in oblique section in Figure 7d, Hemiogordiopsis sp. in horizontal axial section in Figure 7e, and Agathammi$n a$ sp. in vertical axial section and Globivalvulina sp. in oblique section in Figure 7f. Those fossils consti- tute Nankinella/Staffella/Globivalvulina Fauna whose age corresponds to "late Early Permian" (or the age might be "early Late Permian"). We thus consider that the age of limestone at Xiaojiaqiao outcrop is middle Permian. Fossils in Figures 7a to 7d are from the hanging walls of the coseismic slip zone, whereas those in Figures $7 \mathrm{e}$ and $7 \mathrm{f}$ are from footwalls (see depths of samples in the figure caption). Those fossils are basically from the same fauna and there is no clear age difference between both sides of the fault. The fault displacement therefore should not be large and indeed the fault is not drawn as a geological fault in geological map (Figure 1). 



Figure 8 Photomicrographs of host rocks and fault rocks from Xiaojiaqiao outcrop. (a) Bedded limestone in sample D12 (82.8 m depth) with a close-up photograph of an undeformed fossil (probably Palaeotexutularid) on the lower-left corner; (b) sheared bedded limestone with development of solution seams and truncated fossils (surface outcrop about $80 \mathrm{~cm}$ from the coseismic fault to the south); (c) fault breccias close to the coseismic slipping zone in the main fault zone; (d) black gouge on the upper-left side and fault breccias on lower-right side in the main fault zone. (e) foliated cataclasite in sample D09 (48.9 m depth). (f) weakly foliated cataclasite in sample D10 (49.5 m depth); (g) fault breccias containing broken clasts of foliated cataclasite in the main fault zone; (h) fault gouge containing broken clasts of black gouge in the main fault zone. Samples (c), (d), (g) and (h) were collected from the main fault zone close to the coseismic slip zone, near Figure 3e. (c) and (g) were taken under crossed polarized light, whereas all other photomicrographs were taken under plane polarized light. 


\subsection{Microstructures of fault rocks}

From well-developed foliation the bedded limestone (e.g., Figure 6c) appeared to be a deformed rock under naked eyes. Under an optical polarized microscope, however, a fossil (probably Palaeotexutularid) in the rock is nearly undeformed (inset photomicrograph in Figure 8a). Dark-colored solution seams, rich in carbonaceous materials, are locally developed parallel to the bedding plane in the horizontal direction of Figure 8a. Thus bedding-parallel slip may have occurred locally, but most bedded limestone is not deformed much. However, bedded limestone from the footwalls about 80 $\mathrm{cm}$ from the coseismic slip zone is sheared with pervasive development of solution seams and truncated fossils (Figure 8b). Bedded limestone can thus be a site of bedding-parallel slip in limestone.

Typical fault rocks from the main fault zone along the coseismic slip zone are incohesive fault breccia in Figure $8 \mathrm{c}$ and incohesive fault gouge in Figure 8d. Black gouge and brownish gouge under plane-polarized light in Figure 8d correspond to black gouge and yellowish gouge under naked eyes, respectively. Yellowish gouge is more common than the black gouge (Figures 3e and $6 d)$ and is used in our gouge experiments.

Figures 8e and 8f exhibit foliated cataclasite locally found in footwalls in drill cores within $1 \mathrm{~m}$ below the interval of missing cores (Figure 5a). Several clasts containing calcite veins in the upper, middle and lower parts of Figure 8e are elongated with fine-grained matrix forming foliation in horizontal direction. Likewise, vein-containing clasts are deformed with dark-colored matrix to form weak foliation in upper-left to lowerright direction in Figure 8f. Both rocks are cohesive and as hard as host-rock limestone.

The incohesive fault breccia in the main fault zone contains clasts of foliated cataclasite in Figure 8g, and the yellowish gouge contains clasts of black gouge in Figure 8h. Those are clear evidence of reactivated fault motion, destroying previous fault rocks. Thus the main fault zone at Xiaojiaqiao outcrop must have undergone multiple events although fossil data do not indicate very large displacement along this fault.

\section{High velocity friction experi- ments}

\subsection{Experimental procedures}

All experiments were conducted using a new rotary-shear low to high speed frictional testing appara- tus at the State Key Laboratory of Earthquake Dynamics, Institute of Geology, China Earthquake Administration (Figure 9a). An axial force up to $10 \mathrm{kN}$ is applied to a set of solid cylindrical specimens of $40 \mathrm{~mm}$ in diameter using an air actuator at the bottom. A $22 \mathrm{~kW}$ servo-motor is used to rotate one side of the specimen at revolution rates from about 1 to $1500 \mathrm{rps}$. Three different speed ranges are attained using a gear/belt assembly on top of the apparatus, thereby producing a slip rate of several centimeters per year (plate velocity) to a few meters per second (seismic slip rate). We used only the direct line connecting the motor and the sample assembly to produce subseismic to seismic slip rates in our experiments. Torque and axial force are measured with a cantilever-type torque gauge and a force gauge set at the bottom of the loading column (Figure 9a). Axial displacement is measured by using a strain-gauge based displacement transducer attached to the loading column. Rotary motion was detected with a rotary encoder attached to the rotary side of the loading column. Data on torque, axial force, axial displacement, rate of revolution and total number of revolution were recorded with a digital data recorder (KYOWA EDX-100A) with sampling rates of $2000 \mathrm{~Hz}$.

A disadvantage of rotary-shear apparatuses is a large displacement gradient from zero in the center to the maximum at the margin of a specimen. We used the "equivalent slip velocity" $v_{\text {eq }}$, given by $2 \pi R D / 3$ where $R$ is rotation speed (rps) and $D$ is the specimen radius (Hirose and Shimamoto, 2005; Mizoguchi et al., 2009). Note that $v_{\text {eq }}$ is defined such that $\tau v_{\text {eq }}$ gives a rate of frictional work per unit fault area assuming that the shear stress $\tau$ is constant over the fault area. We simply refer $v_{\text {eq }}$ to slip rate or velocity in this paper.

Figure $9 \mathrm{~b}$ shows a schematic diagram of gouge sample assembly. The yellowish gouge from the incohesive fault zone along the coseismic fault was used because this gouge is the most abundant in the fault zone. The yellowish gouge samples of 2.5 to 3.0 grams (about 1.2-1.5 mm thick) were placed between a pair of solidcylindrical specimens of Indian gabbro with $40 \mathrm{~mm}$ in diameter. A hollow-cylindrical Teflon sleeve was used to contain the fault gouge between two specimens. The outer and end surfaces of the specimen were ground with \#150 $(100 \mu \mathrm{m})$ diamond grinding wheel using a cylindrical grinder and the sliding surface was roughened with \#80 $(180 \mu \mathrm{m})$ silicon carbide abrasive to reduce slip along gouge-host rock interfaces. An experiment on rock-on-rock friction was conducted using a block of limestone from the footwalls of the coseismic 
fault because an incohesive fault zone is missing at some places along the coseismic slip zone. A thin fault gouge such as that in Figure $3 \mathrm{f}$ is present at such places and the gouge might have been generated by rock-on-rock frictional sliding during the Wenchuan earthquake. Figure $9 \mathrm{c}$ shows a schematic diagram for the rock-on-rock experiment; a Teflon sleeve is not used and generated gouge can be squeezed out of fault surface.
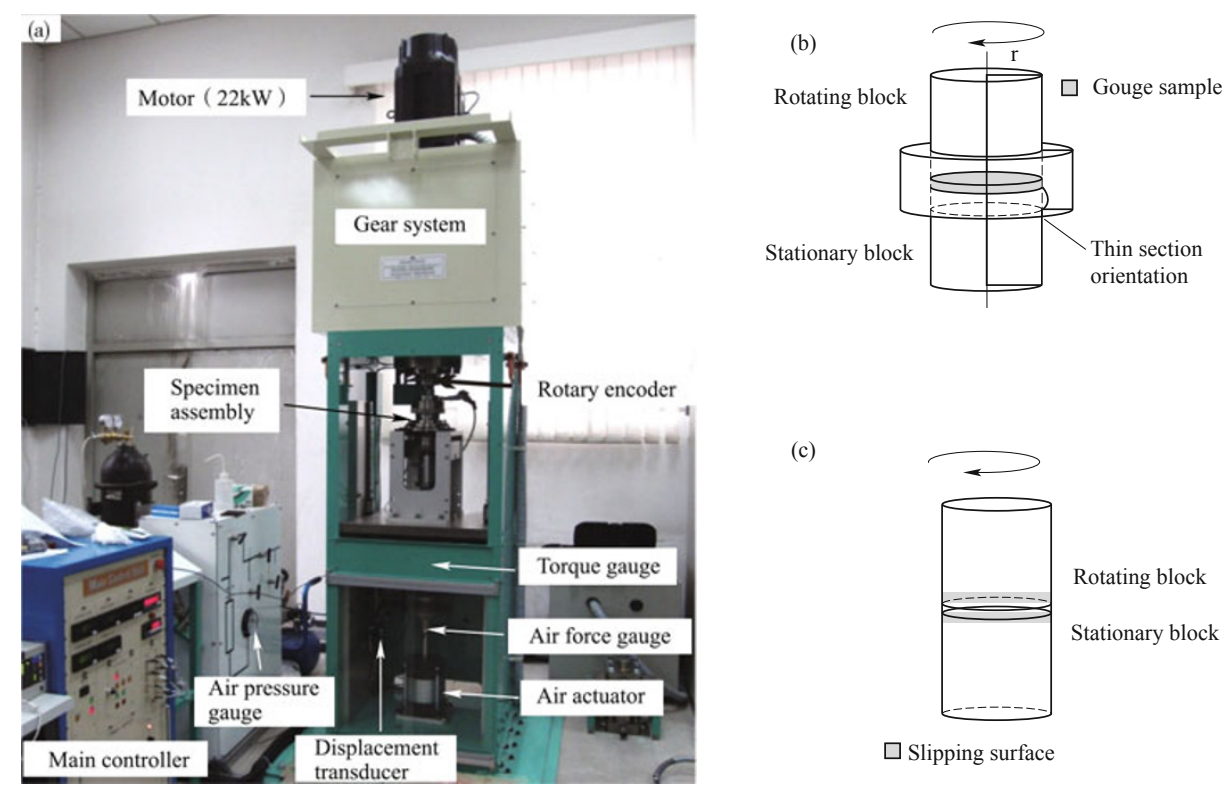

(c)

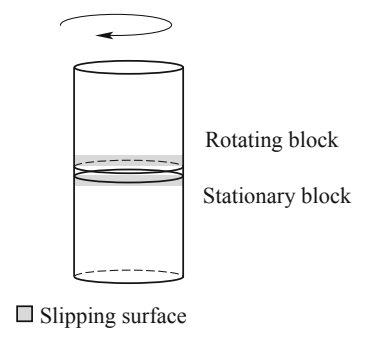

Figure 9 (a) A photograph of rotary-shear low to high-velocity frictional testing machine at Institute of Geology, China Earthquake Administration. (b) A diagram for gouge sample assembly with host rock of Indian gabbro and the thin section orientation for microscopic observations. (c) A diagram showing the specimen assembly for high-velocity experiments of limestone samples from the outcrop close to the fault zone.

For starting a run, a pair of specimens containing the fault gouge is set to the specimen holder and the same axial force as that during the run is applied to pre-compact the gouge. The applied axial force causes axial shortening due to gouge compaction, but the axial shortening stops in several minutes. Then the servomotor is turned on and the speed of the motor is increased to a target value by manually controlling voltage to the motor. Then an electromagnetic clutch is turned on to connect the motor with the rotary side of the specimen to start a run.

The yellowish gouge samples seperately from outcrop and drill core were disaggregated by hand and passed through a $150 \mu \mathrm{m}$ diameter sieve to prepare homogeneous gouge. X-ray diffraction analysis revealed calcite $(87 \%)$ and quartz $(11 \%)$ in the yellowish gouge used for gouge experiments and calcite (84\%) and dolomite (15\%) in host rock limestone used for a rockon-rock friction experiment. Quartz in the gouge probably derived from quartz veins because veins are abun- dant near the fault, and/or it might have come from mudstone between limestone layers.

\subsection{Experimental results}

Fifteen gouge experiments with host rock of Indian gabbro and one rock-on-rock friction experiment on host-rock limestone were conducted successfully with room humidity, at normal stresses of $0.4-1.8 \mathrm{MPa}$ and slip rates of $0.08-1.35 \mathrm{~m} / \mathrm{s}$, and with displacements up to $29 \mathrm{~m}$ (see Figure 10 for experimental results and Table 1 for a summary of experiments). We used the data from experiments where the fault gouge did not leak too much during the slip. The leakage of the gouge was the most difficult technical problem and we made the inner diameter of the Teflon sleeve smaller than the diameter of the host rock by about $130 \mu \mathrm{m}$ to prevent the gouge leakage (see Appendix of Sawai et al. (2012) for problems caused by Teflon sleeve).

Figure 10a shows friction coefficient versus displacement curves for yellowish gouge deformed dry at a slip rate of $1.3 \mathrm{~m} / \mathrm{s}$ and at normal stresses of $0.4-1.8$ 
Table 1 A list of experiments with experimental conditions, slip-weakening parameters and the specific fracture energy

\begin{tabular}{cccccccc}
\hline $\begin{array}{c}\text { Sample } \\
\text { No. }\end{array}$ & $\begin{array}{c}\text { Sample } \\
\text { type }\end{array}$ & $\begin{array}{c}\text { Normal } \\
\text { stress } / \mathrm{MPa}\end{array}$ & $\begin{array}{c}\text { Slip } \\
\mathrm{rate} /\left(\mathrm{m} \cdot \mathrm{s}^{-1}\right)\end{array}$ & $\mu_{\mathrm{p}}$ & $\mu_{\mathrm{ss}}$ & $\begin{array}{c}D_{\mathrm{c}} \\
/ \mathrm{m}\end{array}$ & $\begin{array}{c}\text { Specific fracturer } \\
\text { energy } E_{\mathrm{G}} /\left(\mathrm{MN} \cdot \mathrm{m}^{-1}\right)\end{array}$ \\
\hline LHV047 & Outcrop gouge & 1.00 & 1.30 & 0.58 & 0.17 & 4.88 & 0.67 \\
LHV049 & Outcrop gouge & 0.60 & 1.30 & 0.54 & 0.11 & 13.71 & 1.11 \\
LHV051 & Outcrop gouge & 0.40 & 1.30 & 0.56 & 0.13 & 26.51 & 1.66 \\
LHV054 & Outcrop gouge & 1.80 & 1.30 & 0.55 & 0.11 & 4.50 & 1.15 \\
LHV060 & Outcrop gouge & 1.40 & 1.30 & 0.56 & 0.12 & 4.82 & 1.02 \\
LHV061 & Outcrop gouge & 1.00 & 0.40 & 0.64 & 0.29 & 17.19 & 2.89 \\
LHV062 & Outcrop gouge & 1.00 & 0.20 & 0.68 & 0.43 & $\mathrm{~N} / \mathrm{A}$ & $\mathrm{N} / \mathrm{A}$ \\
LHV063 & Outcrop gouge & 1.00 & 0.60 & 0.62 & 0.21 & 7.98 & 1.18 \\
LHV064 & Outcrop gouge & 1.00 & 0.80 & 0.64 & 0.18 & 4.36 & 0.59 \\
LHV065 & Outcrop gouge & 1.00 & 1.08 & 0.63 & 0.13 & 5.52 & 0.92 \\
LHV070 & Outcrop gouge & 1.00 & 1.35 & 0.59 & 0.12 & 4.99 & 0.76 \\
LHV071 & Outcrop gouge & 1.00 & 0.08 & 0.68 & 0.60 & $\mathrm{~N} / \mathrm{A}$ & $\mathrm{N} / \mathrm{A}$ \\
LHV075 & Outcrop gouge & 0.80 & 1.30 & 0.53 & 0.10 & 7.76 & 1.01 \\
LHV102 & Limestone rock & 1.00 & 1.30 & 0.69 & 0.16 & 5.12 & 0.82 \\
LHV182 & Drilling gouge & 1.00 & 1.30 & 0.53 & 0.14 & 5.02 & 0.82 \\
LHV185 & Drilling gouge & 1.80 & 1.30 & 0.56 & 0.11 & 4.23 & 1.24 \\
\hline
\end{tabular}

Note: $\mu_{\mathrm{p}}$ and $\mu_{\mathrm{ss}}$ denotes peak and steady-state friction coefficients, respectively, and $D_{\mathrm{c}}$ is the slip weakening distance [see equation (1)]. N/A indicates that the value could not be determined from experimental data.

MPa as given for each curve. Gouge exhibits dramatic slip-weakening from peak friction coefficient $\mu_{\mathrm{p}}$ to nearly steady-state friction coefficient $\mu_{\mathrm{ss}}$ in all cases. The post-peak slip-weakening can be described by an empirical equation proposed by Mizoguchi et al. (2007):

$$
\mu(d)=\mu_{\mathrm{ss}}+\left(\mu_{\mathrm{p}}-\mu_{\mathrm{ss}}\right) \exp \left(\frac{\ln 0.05 d}{D_{\mathrm{c}}}\right),
$$

where $\mu$ is the friction coefficient at post-peak displacement $d$, and $D_{\text {c }}$ is the slip weakening distance defined as the displacement corresponding to the $95 \%$ reduction in friction coefficient from $\mu_{\mathrm{p}}$ to $\mu_{\mathrm{ss}}$. Note that $\mu-\mu_{\mathrm{ss}}=0.05\left(\mu_{\mathrm{p}}-\mu_{\mathrm{ss}}\right)$ when $d=D_{\mathrm{c}}$, confirming the definition of $D_{\mathrm{c}}$. The $95 \%$ reduction in friction was used in the definition of $D_{\mathrm{c}}$ to make it similar to an ordinary definition of $D_{\mathrm{c}}$ in the linear slip weakening law (i.e., $D_{\mathrm{c}}$ is the displacement from the peak to the steady-state friction). A representative example in Figure 11 demonstrates that the slip-weakening behavior can be fit well with equation (1).

Shear stresses are plotted against the normal stresses in open circles for the peak friction and in open squares for the steady-state friction in Figure 10b, using the original data in Figure 10a before the correction of Teflon friction to be explained below. In both cases the shear stress is in linear proportion to the normal stress, but the lines fit with the least-squares method have intercepts of $0.084 \pm 0.009 \mathrm{MPa}$ for the peak friction and $0.077 \pm 0.010 \mathrm{MPa}$ for the steady-state friction. Those intercepts have been interpreted as an increase in shear stress due to friction between Teflon sleeve and a speci- men (Mizoguchi et al., 2007; Togo et al., 2011a; Sawai et al., 2012). We also consider the intercepts due to Teflon friction. Teflon friction is estimated from the intercepts in Figure 10b only at peak friction and at steady-state friction. Those were subtracted from the shear stresses in Figure 10b to obtain solid circles for peak friction and solid squares for steady-state friction. Coulomb's law of friction now holds with peak and steady-state friction coefficients of $0.547 \pm 0.009$ and $0.116 \pm 0.010$, respectively. To correct for the Teflon friction for the entire run, we followed a method of Togo et al. (2011a) and assumed that the Teflon friction linearly increases from zero to peak friction and then decreases exponentially to steady-state value as described by equation (1) using $D_{\text {c }}$ determined for gouge. We subtracted the Teflon friction thus estimated from the measured shear stress in all runs shown in Figures 10 and 11.

Figure 10c shows friction coefficient plotted against fault displacement for the yellowish gouge deformed dry at a normal stress of 1.0 MPa and at seven different slip rates as shown for each curve. At the highest slip rate of $1.35 \mathrm{~m} / \mathrm{s}$, the peak friction of 0.60 is followed by marked slip weakening towards nearly steady-state friction of about 0.12 . The peak friction remains high for all slip rates, but the steady-state friction decreases with increasing slip rate. When slip rate is less than $0.4 \mathrm{~m} / \mathrm{s}$, a fault is very unstable and often exhibits large fluctuation of shear stress (pale green and light blue lines in Figure 10c). This is often caused by distortion of Teflon sleeve and partial leakage of gouge (see Appendix of 
Sawai et al. (2012) for the behavior of Teflon sleeve during intermediate to high velocity experiments).

Figure 10d displays a comparison of frictional behavior at a slip rate of $1.3 \mathrm{~m} / \mathrm{s}$ among different samples. Two experiments were conducted at normal stresses of
1.0 and $1.8 \mathrm{MPa}$, respectively, using the yellowing gouge from the outcrop and from the drill cores. The behaviors for the four cases are quite similar (Figure 10d). One result from rock-on-rock friction experiment is also similar to the results from gouge experiments.
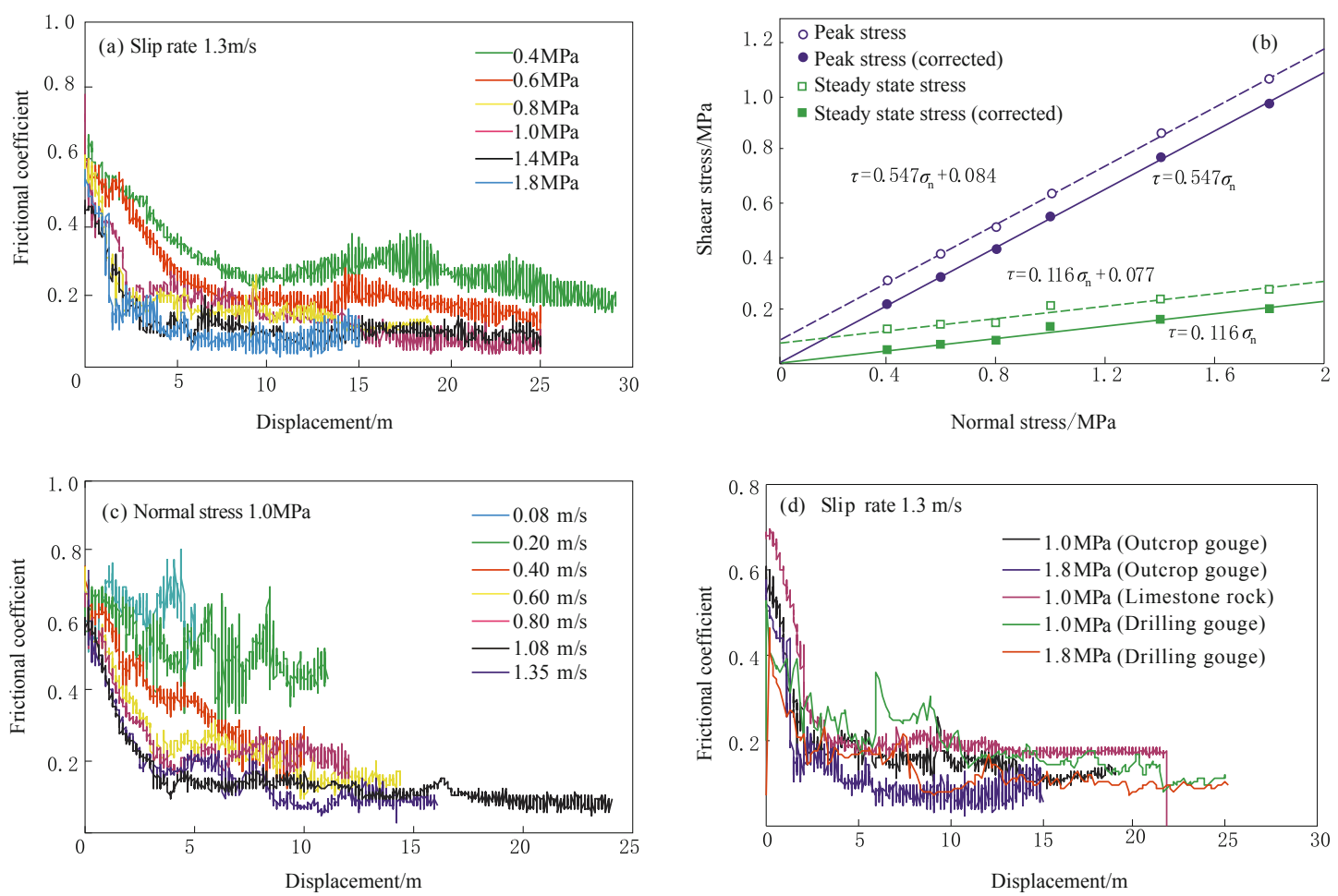

Figure 10 Experimental results for gouge from Xiaojiaqiao outcrop and for the host rock limestone deformed at intermediate to high-velocities. (a) Friction coefficient versus displacement curves for gouge from surface outcrop deformed dry at a slip rate of $1.3 \mathrm{~m} / \mathrm{s}$ and at normal stresses of 0.4 to $1.8 \mathrm{MPa}$ as shown for each curve. (b) Shear stress plotted against normal stress for six outcrop gouge samples deformed dry at a slip rate of $1.3 \mathrm{~m} / \mathrm{s}$ (circles: data for the peak friction, squares: data for the nearly steady-state friction, open symbols: original data, filled symbols: data after the correction of measured shear stress for the friction of Teflon ring). (c) Friction coefficient plotted against the displacement for gouge from surface outcrop deformed dry at a normal stress of $1.0 \mathrm{MPa}$ and at slip rates of 0.08 to $1.35 \mathrm{~m} / \mathrm{s}$ as given for each curve. (d) Friction coefficient versus displacement curves compared for outcrop gouge, host rock limestone and drill-core gouge, deformed at a slip rate of $1.3 \mathrm{~m} / \mathrm{s}$ and at a normal stress of 1.0 or $1.8 \mathrm{MPa}$ as given for each curve.

\subsection{Slip-weakening parameters and specific fracture energy $\boldsymbol{E}_{\mathrm{G}}$}

We now care about how slip-weakening parameters (Figure 11) in equation (1) change with experimental conditions. All parameters were determined after correcting the measured shear stress for the Teflon friction and are given in Table 1. For yellowish gouge deformed dry at a normal stress of $1 \mathrm{MPa}$, the peak friction coefficient $\mu_{\mathrm{p}}$ is nearly constant $(0.59-0.68)$ although it may decrease slightly with increasing slip rate (Table 1). Whereas the steady-state friction coefficient $\mu_{\mathrm{ss}}$ decreases from 0.6 to 0.12 as the slip rate increases from 0.08 to $1.3 \mathrm{~m} / \mathrm{s}$ (Figure 12a). This decrease in steady-state friction can be described by an empirical equation proposed in Togo et al. (2011a):

$$
\mu_{\mathrm{ss}}(v)=\left.\mu_{\mathrm{ss}}\right|_{v=\infty}+\left(\left.\mu_{\mathrm{ss}}\right|_{v=0}-\left.\mu_{\mathrm{ss}}\right|_{v=\infty}\right) \exp \left(\frac{-v}{v_{\mathrm{c}}}\right),
$$

where $\mu_{\mathrm{ss}}(v)$ is the steady state friction at a slip rate $v$, and $v_{\mathrm{c}}$ is the critical weakening velocity specifying how rapidly $\mu_{\mathrm{ss}}$ decreases with increasing slip rate. Note that $\mu_{\mathrm{ss}}$ decreases exponentially from $\mu_{\mathrm{ss}}$ at a slip rate of zero 
to $\mu_{\mathrm{ss}}$ at an infinite slip rate. Equation (2) cannot describe slip rate dependence of friction at slow slip rate (e.g., velocity strengthening and velocity weakening). However, it describes the dramatic weakening as slip rate increases from subseismic to seismic slip rate with constants $\left.\mu_{\mathrm{ss}}\right|_{v=0}=0.74 \pm 0.02,\left.\mu_{\mathrm{ss}}\right|_{v=\infty}=0.12 \pm 0.01$ and $v_{\mathrm{c}}=0.31 \pm 0.02 \mathrm{~m} / \mathrm{s}$ (Figure 12a). Only results from present work, shown in filled squares, were used to determine the constants by the least squares fitting using Origin software.

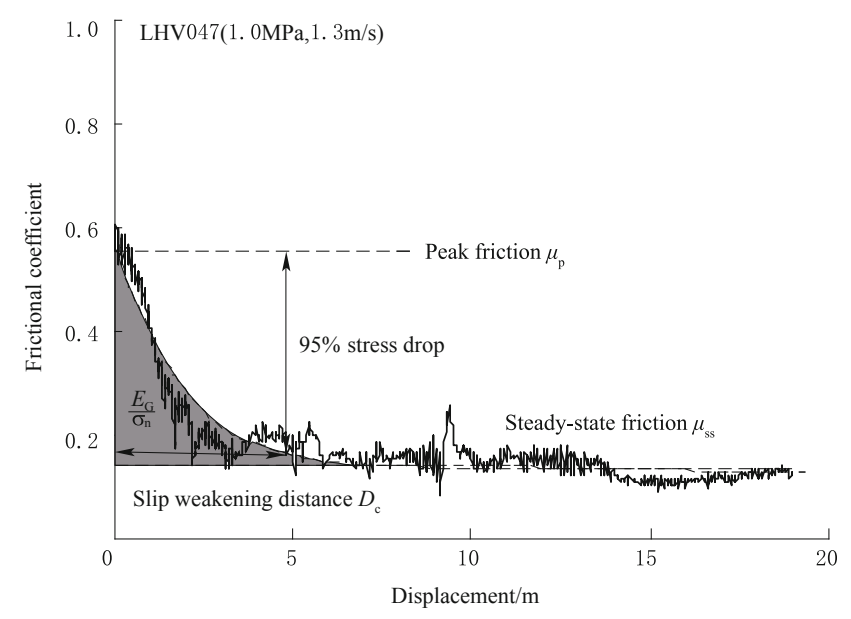

Figure 11 A representative experimental result for fitting the slip-weakening law (run LHV047; yellowish gouge deformed dry at a normal stress of 1.0 MPa and a slip rate of $1.3 \mathrm{~m} / \mathrm{s}$ ). An experimental result is shown in solid line on friction coefficient versus displacement diagram, and dashed line gives the least squares fit with equation (1). Peak friction coefficient $\mu_{\mathrm{p}}$, the slip weakening distance $D_{\mathrm{c}}$ and the steady-state frictional coefficient $\mu_{\mathrm{ss}}$ were determined as $0.58,4.88 \mathrm{~m}$ and 0.17 , respectively, using Origin software. The stippled area beneath the slipweakening curve gives the fracture energy $E_{\mathrm{G}}$ normalized with respect to the normal stress $\sigma_{\mathrm{n}}$.

Slip weakening distance $D_{\mathrm{c}}$ specifies how rapidly friction coefficient drops from peak to steady-state values and is a very important parameter for controlling fault instability (e.g., Dieterich, 1978). $D_{\text {c }}$ decreases from $26.5 \mathrm{~m}$ to $4.5 \mathrm{~m}$ as a normal stress increases from 0.4 to $1.8 \mathrm{MPa}$ for yellowish gouge deformed dry at a slip rate of $1.3 \mathrm{~m} / \mathrm{s}$ (Figure $12 \mathrm{~b}$ ). Likewise $D_{\mathrm{c}}$ decreases from $17.2 \mathrm{~m}$ to $5.0 \mathrm{~m}$ as a slip rate increases from 0.4 to $1.35 \mathrm{~m} / \mathrm{s}$ for the same gouge deformed dry at a normal stress of $1.0 \mathrm{MPa}$ (Figure 12c). An empirical power laws $\left(D_{\mathrm{c}}=(6.12 \pm 0.07) \sigma_{\mathrm{n}}^{-(1.6 \pm 0.1)}\right.$ and $D_{\mathrm{c}}=$ $\left.(4.56 \pm 0.05) v^{-(1.4 \pm 0.3)}\right)$ can describe our experimental results reasonably well (compare solid curves with filled squares in Figures $12 \mathrm{~b}$ and 12c), as shown by Togo et al. (2011a).

The fracture energy $E_{\mathrm{G}}$ is the energy that controls the dynamic rupture propagation and an important parameter that can be determined seismically (e.g., Tinti et al., 2005). The specific fracture energy $\left(E_{\mathrm{G}}\right.$ divided by the normal stress) is the area underneath the slip weakening curve (Figure 11; e.g., Mizoguchi et al., 2007). Here we used equation (4) of Togo et al. (2011a) to calculate the specific fracture energy which was derived by integrating the slip weakening curve, equation (1), with respect to displacement from zero to infinity. Specific fracture energy from our study ranges 0.6-2.9 $\mathrm{MN} / \mathrm{m}$ (Table 1) and it tends to decrease slightly with increasing normal stress although data points are scattered (Figure 12d).

\subsection{Microstructures of deformed yellowish gouge}

Preliminary observation of gouge textures was made under a polarized optical microscope on thin sections of deformed yellowish gouge. Thin sections were made normal to gouge layer and parallel to the cylindrical specimen (black solid line in Figure 9b). Because thin sections go through the center of specimen, the sliding direction is normal to the thin sections and the orientation of thin sections is not good for observing shear structures. But overall textures can be seen well with the thin sections, as done by Kitajima et al. (2010). Figure 13 gives microstructures under plane-polarized light for three representative samples of yellowish gouge deformed dry at normal stresses of 0.4 to $1.0 \mathrm{MPa}$ and slip rates of 0.6 to $1.3 \mathrm{~m} / \mathrm{s}$.

We recognized three distinct gouge units based on the grain size, grain shape, foliation and presence of localized slip surface, following the concept of Kitajima et al. (2011). Unit 1 is extremely fine-grained and highly sheared zone with well-developed foliation, constituting slip zone. This unit is developed in most cases close to the boundary with the moving side of the host rock and often forms complex structures by overlapping slip zones in gouge deformed at a high normal stress and at a high slip rate. Unit 2 is moderately deformed structureless zone with more reduced sizes of clasts and with light brownish color probably due to oxidation of iron minerals due to frictional heating. Unit 3 is weakly deformed zone normally developed adjacent to the stationary side of the host rock and consists of angular clasts of carbonate grains without displaying flattened grains and with somewhat reduced particle sizes from the initial gouge. 



Figure 12 Slip weakening parameters and specific fracture energy $E_{\mathrm{G}}$ for yellowish gouge from Xiaojiaqiao outcrop from our experiments (filled symbols) (see Table 1 for compiled data). (a) Steady state frictional coefficient versus slip rate for the outcrop gouge deformed dry at a normal stress of 1.0 MPa. (b) Slip weakening distance $D_{\text {c }}$ plotted against the normal stress for gouge deformed dry at a slip rate of $1.3 \mathrm{~m} / \mathrm{s}$. (c) $D_{\text {c plotted }}$ against the slip rate for the same gouge sample deformed dry at a normal stress of $1.0 \mathrm{MPa}$. (d) Specific fracture energy $E_{\mathrm{G}}$ plotted against the normal stress for the outcrop gouge deformed dry at a slip rate of 1.3 $\mathrm{m} / \mathrm{s}$. Our results are compared with results from other studies (open circles for Yingxiu-Beichuan fault zone at Hongkou outcrop by Togo et al., 2011a; open squares for Pingxi fault zone by Yao et al., 2011).

Gouge deformed at a low normal stress has a simple structure characterized by very narrow slip zone (unit 1), moderately deformed zone (unit 2) next to the slip zone, and weakly deformed zone (unit 3 ) on the stationary side of gouge (Figures 13a and 13b; gouge deformed at a normal stress $\sigma_{\mathrm{n}}$ of $0.4 \mathrm{MPa}$ and at a slip rate $v$ of $1.3 \mathrm{~m} / \mathrm{s})$. Typical thickness of the slip zone is about 30 $\mu \mathrm{m}$, but it locally varies from several to about $60 \mu \mathrm{m}$. This is a typical width of slip zone reported previously (e.g., Sawai et al., 2012). The white line near the upper boundary of gouge in Figure 13a is separation in gouge during the process of making the thin section (thus no gouge material there). Gouge is separated often at slickenside surface and in this case it was separated along the boundary between units 1 and 2. Slip zone or unit 1 does not contain any visible clasts even under a high magnification of an optical microscope. The zone extincts simultaneously suggesting preferred orientation of phyllosilicate minerals.

Gouge deformed at a higher normal stress, but at a slower slip rate $\left(\sigma_{\mathrm{n}}=1.0 \mathrm{MPa}\right.$ and $\left.v=0.6 \mathrm{~m} / \mathrm{s}\right)$ exhibits basically the same structure (Figures 13c and 13d), ex- cept that the slip zone is wider than those in the above cases $(20-100 \mu \mathrm{m}$ in this example). However, complex overlapped structures of slip zone formed locally in the same specimen as shown under a high magnification in Figures 13e and 13f. Four slip zone units (SZ1 to SZ4) were recognized as annotated in the sketch. Slip zone unit SZ4 (about $100 \mu \mathrm{m}$ in width) appears to cut SZ1 and SZ3 and was probably the active slip zone at the end of experiment. Slip zone units SZ1 to SZ3 consist of highly sheared unit 1 and moderately deformed unit 2 , but deformation changes gradually between the two in each slip zone unit (observe Figure 13e closely). Boundaries between the slip-zone units appear to be sharp. Such slip zone structures are quite similar to those reported recently by Togo and Shimamoto (2012) and Sawai et al. (2012) who recognized that grains in moderately deformed zone are welded or sintered (they could not observe individual grains in highly sheared zones even under a FE-SEM). It is thus likely that slip zone and welded zone become strong once constituent grains are welded and they cannot be sheared easily, resulting in a shift of slipping zone. Welded zone 



Figure 13 Photomicrographs of deformed yellowish gouge from surface outcrop under plane polarized light and their schematic sketches. (a) and (b): Gouge deformed at a normal stress of $0.4 \mathrm{MPa}$ and a slip rate of $1.3 \mathrm{~m} / \mathrm{s}$ (run LHV051; see Table 1); (c) to (f): gouge deformed at $1.0 \mathrm{MPa}$ and $0.6 \mathrm{~m} / \mathrm{s}$ (run LHV063); and (g) and (h): gouge deformed at $1.0 \mathrm{MPa}$ and $1.3 \mathrm{~m} / \mathrm{s}$ (run LHV047). In all photomicrographs host rocks can be seen at the top. Units 1, 2 and 3 are highly-deformed slip zone, moderately deformed zone and weakly deformed zone, respectively. SZ1 to SZ4 in (f) are slip-zone units as described in the text. White areas in gouge are portions of missing gouge. Notable clasts are traced in the sketches. 
often form overlapped structures locally, but is missing at other places in the specimens reported by those authors and in our specimen as well.

Gouge deformed at $\sigma_{\mathrm{n}}=1.0 \mathrm{MPa}$ and $v=1.3 \mathrm{~m} / \mathrm{s}$ (higher slip rate than in the previous case) exhibits even more complex structure than in the previous examples (Figures 13g and 13h). The last active slip zone is developed at the gouge-moving block boundary at the top of gouge. However, there is another fragment of slip zone (unit 1) at the lower-middle part of photomicrograph which changes gradually upwards to unit 2 and then to unit 3. The units 1 and 2 are adjacent to unit 3 at the bottom by a sharp boundary concave upward. This structure is more complex than the overlapped structures and we are not certain how it developed. However, the gouge in this run was squeezed out and the final thickness of gouge was reduced to $1 / 4$ or $1 / 5$ of the original thickness. Continuous gouge zone remained on the fault and the mechanical behavior was consistent with other results, so that we included this run in this paper. But the loss of substantial amount of gouge must have resulted in complex deformation forming structure like the one in Figures 13g and 13h. Thus the strengthening of gouge due to grain welding and squeezing out of gouge seem to cause formation of complex structures in gouge deformed at a high slip rate and at a high normal stress.

\section{Discussion}

A motivation for studying the fault at Xiaojiaqiao outcrop was the paper by Li et al. (2008) who reported coseismic vertical displacement during the Wenchuan earthquake exceeding $5 \mathrm{~m}$ at this outcrop and considered that the fault is near Yingxiu-Beichuan fault, and moved during the Wenchuan earthquake. But we have shown in this paper that the fault is located about 3 $\mathrm{km}$ to the south from Yingxiu-Beichuan fault, that the coseismic displacement can be on the order of $0.5 \mathrm{~m}$ although the estimate is not accurate, and that the displacement along the fault is not large in view of the same fossil assembly on both side of the fault. The outcrop is located in the Anxian transfer zone between the northern and central segments of the Yingxiu-Beichuan fault (Jin et al., 2010). We are convinced now that the fault at Xiaojiaqiao outcrop is a small subsidiary fault activated by the Wenchuan earthquake.

A purpose of present study was to study highvelocity frictional behavior of fault gouge, using a new rotary-shear low to high-velocity friction apparatus, to get some insight on the response of shallow fault zone to the dynamic rupture during the Wenchuan earthquake. Frictional properties at low slip rates (e.g., Verberne et al., 2010) may control the nucleation of earthquake, but the fault at Xiaojiaqiao outcrop is not near the epicenter of the Wenchuan earthquake. Moreover, another purpose of this study is to examine the heterogeneity in frictional properties along faults. Heterogeneity in fault properties is a fundamental feature of fault properties, but no systematic studies have been conducted to our knowledge. We recognized dramatic slip weakening at high slip rates and our results are quite similar to those from previous studies (Mizoguchi, 2007; Hirose and Bystricky, 2007; Han et al., 2007a, 2010; Brantut et al., 2008; De Paola et al., 2011; Di Toro et al., 2011) despite variation in gouge materials. Moreover, Figure 12 shows a comparison in the slip weakening parameters from this study (filled squares) with those by Togo et al. (2011a) for pelitic gouge from Hongkou outcrop of Yingxiu-Beichuan fault zone and by Yao et al. (2011) for fault gouge from Kuangpingzi outcrop of Pingxi fault zone. Our results for a fault in limestone coincide nearly quantitatively with those for the other two faults formed in sedimentary rocks, mostly pelitic and psammitic rocks. High-velocity frictional properties of the Longmenshan fault system may be homogeneous although we will check this point by further studies for different outcrops and drill cores.

Several mechanisms have been proposed recently to account for the high-velocity weakening of faults. These mechanisms include flash heating (Rice, 1999, 2006; Beeler et al., 2008; Rempel, 2006; Rempel and Weaver, 2008; Bizzarri, 2009; Kohli et al., 2011; Goldsby and Tullis, 2011). Other proposed weakening mechanisms are thermal decomposition (Han et al., 2007a, 2007b; Hirose and Bysricky, 2007; Brantut et al., 2008; De Paola et al., 2011) and nanoparticles or powder lubrication (Han et al., 2010, 2011; Reches and Lockner, 2010; Di Toro et al., 2011). Unfortunately, our preliminary textural analysis could not delineate important mechanism(s) for dramatic high-velocity weakening. $\mathrm{XRD}$ analysis revealed that the yellowish gouge contains calcite $82 \%$ and quartz $10 \%$. Thus the calcite in the yellowish gouge might have undergone decomposition which requires temperature reaching to $900^{\circ}$ (Deer et al., 1992). However, our XRD analysis was not sensitive enough to detect mineralogical changes in the gouge zone. More detailed work is needed in the future to identify the mechanism(s).

Since Brace and Byerlee (1966) proposed "stick- 
slip" as a mechanism of earthquake, frictional properties of faults at low slip rates $(<0.01 \mathrm{~m} / \mathrm{s})$ and at small displacement $(<20 \mathrm{~mm})$ have been studied in detail in laboratory experiments (e.g., Marone, 1998). An establishment of rate and state fault constitutive law has lead to great successes in earthquake modeling (Dieterich, 1979; Ruina, 1983). However, there still remain an important unsolved problem in seismic fault motion that cannot be explained with fault properties at slow slip rates (Mizoguchi et al., 2009). One problem is the slip weakening distance and fracture energy of seismic faults during earthquake rupture. Slip-weakening distance of faults inferred from seismic wave analysis ranges between 0.2 and $1 \mathrm{~m}$ (Ide and Takeo, 1997; Olsen et al., 1997), whereas laboratory experiments at slow rate and small slip yielded the values typically of the order of $10 \mu \mathrm{m}$ (Dieterich, 1978; Ohnaka and Yamashita, 1989). On the other hand, the slip weakening distance $D_{\mathrm{c}}$ ranged from 4 to $26 \mathrm{~m}$ in our experiments. There is a scale issue in this problem as difficult future task; in the high velocity regime $D_{c}$ tends to be smaller with increasing normal stress or with increasing slip rate. Thus large $D_{\text {c }}$ at high velocities tends to approach towards seismically determined values at deeper conditions. However, slip zone is wider for natural faults than in out experiments and wider slip zone will make $D_{\text {c greater. We still }}$ cannot predict $D_{\text {c }}$ for natural faults. Further integrated studies on natural faults and laboratory experiments are needed in the future.

Specific fracture energy $E_{\mathrm{G}}$ is another quantity that may be compared with seismologically determined values. Values we obtained $(0.5-3 \mathrm{MN} / \mathrm{m})$ are consistent with previous experimental results (Mizoguchi et al., 2007, 1-3 MN/m; De Paola et al., 2011, 0.5-5 $\mathrm{MN} / \mathrm{m}$; Togo et al., 2011a, 1-4 MN/m). And those values are consistent with seismically determined values for the Kobe, California and other earthquakes (Rice, 2006; Mizoguchi et al., 2007; De Paola et al., 2011).

\section{Conclusions}

The main conclusions of this study are summarized below.

Xiaojiaqiao outcrop is a small-scale beddingparallel fault in limestone of late Early Permian age, located in the Anxian transfer zone between the northern and central segments of the Yingxiu-Beichuan fault. The fault zone is about $40 \mathrm{~m}$ wide and is characterized by the formation of gentle folds and internal small-scale faults. Coseismic displacement on the order of $0.5 \mathrm{~m}$ occurred along the main fault zone during Wenchuan earthquake. This displacement corresponds to earthquake magnitude of about 6.5 in view of Wells and Coppersmith (1994). The fault has a similar strike to the Yingxiu-Beichuan fault and a dip of $38^{\circ} \mathrm{NW}$. Thus the fault is nearly optimally oriented for thrust motion and is an example of subsidiary faults that were activated by the 2008 Wenchuan earthquake.

The main fault zone consists of fault breccia and fault gouge which contain broken fragments of foliated cataclasite and black gouge. The re-working of old fault rocks is a clear evidence of multiple events along this fault. However, fossil assembly is the same on both side of the coseismic fault so that the displacement along the fault is unlikely to be large.

Rotary-shear frictional experiments at subseismic to seismic slip rate revealed dramatic slip weakening of yellowish gouge, and slip weakening parameters for gouge from Xiaojiaqiao outcrop agree quantitatively with those reported for gouge from Hongkou outcrop and Pingxi outcrop, despite the differences in the host rocks and fault-zone mineralogy. Specific fracture energy of yellowish gouge is $0.5-3 \mathrm{MN} / \mathrm{m}$ and is of the same order as those of natural earthquakes. Rock-onrock friction of host-rock limestone exhibits very similar behavior to that of the yellowish gouge. Deformed yellowish gouge is characterized by highly deformed slip zone (unit 1), moderately deformed zone (unit 2) and weakly deformed zone (unit 3). Complex structures such as overlapped slip zones formed in gouge deformed at a high normal stress and a high slip rate due to strengthening of slip zone caused by the grain welding due to frictional heating.

Acknowledgements The authors thank two anonymous reviewers for giving many useful comments and suggestions. We also thank members of rock deformation group of the State Key Laboratory of Earthquake Dynamics, Institute of Geology, CEA, for many useful discussions. Yongsheng Zhou, Yongxin Yang, and Lei Zhang participated into early stage of work at Xiaojiaqiao outcrop. This work was financially supported by State Key Laboratory of Earthquake Dynamics (project No. LED2010A05, LED2010A03) and Wenchuan Earthquake Fault Scientific Drilling Project (WFSD).

\section{References}

Beeler N M, Tullis T E and Goldsby D L (2008). Constitutive relationships and physical basis of fault strength due to flash heating. J Geophys Res 113: B01401, 
doi:10.1029/2007JB004988.

Bizzarri A (2009). Can flash heating of asperity contacts prevent melting? Geophys Res Lett 36: L11304, doi:10.1029/2009GL037335.

Brace W F and Byerlee J D (1966). Stick-slip as a mechanism for earthquakes. Science 153: 990-992.

Brantut N, Schubnel A, Rouzaud J N, Brunet F and Shimamoto $\mathrm{T}$ (2008). High velocity frictional properties of a clay-bearing fault gouge and implications for fault mechanics. J Geophys Res 113: B10401.

Chang C P, Chen G H, Xu X W, Yuan R M, Kuo Y T and Chen W S (2012). Influence of the pre-existing Xiaoyudong salient in surface rupture distribution of the $M_{\mathrm{W}} 7.9$ Wenchuan earthquake, China. Tectonophysics 530-531: 240-250.

Chen J, Yang X, Dang J, He C, Zhou Y and Ma S (2011). Internal structure and permeability of Wenchuan earthquake fault. Chinese J Geophys 54(7): 1 805-1 816 (in Chinese with English abstract).

Deer W A, Howie R A and Zussman J (1992). An Introduction to the Rock-Forming Minerals. Edition 2. Longman Scientific and Technical. Harlow, UK.

De Paola N, Hirose T, Mitchell T, Mitchell T, Di Toro G, Viti C and Shimamoto T (2011). Fault lubrication and earthquake propagation in thermally unstable rocks. Geology 39(1): 35.

Dieterich J H (1978). Time dependent friction and the mechanics of stick slip-slip. Pure Appl Geophys 116(4): 790-806.

Dieterich J H (1979). Modeling of rock friction: 1. Experimental results and constitutive equations. J Geophys Res 84(B5): 2 161-2 168.

Di Toro G, Han R, Hirose T, De Paola N, Nielsen S, Mizoguchi K, Ferri F, Cocco M and Shimamoto T (2011). Fault lubrication during earthquakes. Nature 471: 494498.

Fu B, Shi P, Guo H, Okuyama S, Ninomiya Y and Wright S (2011). Surface deformation related to the 2008 Wenchuan earthquake, and mountain building of the Longmen Shan, eastern Tibetan Plateau. J Asian Earth Sci 40: 805-824.

Goldsby D L and Tullis T E (2011). Flash heating leads to low frictional strength of crustal rocks at earthquake slip rates. Science 334: 216-218.

Han L, Zhou Y, Chen J, Ma S, Yang X, He C and Dang J (2010). Structural characters of co-seismic fault gouge in bed rocks during the Wenchuan earthquake. Quaternary Sciences 30: 745-758, doi:10.3969/j.issn.10017410.2010.04.10 (in Chinese with English abstract).

Han R, Shimamoto T, Ando J and Ree J (2007a). Seismic slip record in carbonate-bearing fault zones: An insight from high-velocity friction experiments on siderite gouge. Geology 35(12): 1 131-1 134.

Han R, Shimamoto T, Hirose T, Ree J H and Ando J (2007b). Ultralow friction of carbonate faults caused by thermal decomposition. Science 316: 878-881.

Han R, Hirose T and Shimamoto T (2010). Strong velocityweakening and powder lubrication of simulated carbonate faults at seismic slip rates. J Geophys Res 115: B03412, doi:10.1029/2008JB006136

Han R, Hirose T, Shimamoto T, Lee Y and Ando J (2011). Granular nanoparticles lubricate faults during seismic slip. Geology 39(6): 599-602.

Hirose T and Bystricky M (2007). Extreme dynamic weakening of faults during dehydration by coseismic shear heating. Geophys Res Lett 34: L14311, doi:10.1029/ 2007GL030049.

Hirose T and Shimamoto T (2005). Growth of a molten zone as a mechanism of slip weakening of simulated faults in gabbro during frictional melting. $J$ Geophys Res 110(B5): B05202.

Ide S and Takeo M (1977). Determination of constitutive relations of fault slip based on seismic wave analysis. $J$ Geophys Res 102: 379-391.

Jin W, Tang L, Yang K, Wan G and Lu Z (2010). Segmentation of the Longmen Mountains thrust belt, Western Sichuan Foreland Basin, SW China. Tectonophysics 485 : 107-121.

Kitajima H, Chester J S, Chester F M and Shimamoto T (2010). High-speed friction of disaggregated ultracataclasite in rotary shear: Characterization of frictional heating, mechanical behavior, and microstructure evolution. $J$ Geophys Res 115: B08408.

Kohli A H, Goldsby D L, Hirth G and Tullis T E (2011). Flash weakening of serpentinite at near seismic slip rates. $J$ Geophys Res 116(B3): B03202.

Li X, Yu G and Xu X (2008). Surface ruptures in bed rock of the $M_{\mathrm{S}} 8.0$ Wenchuan earthquake. Seismology and Geology 33: 899-995 (in Chinese with English abstract).

Li H, Si J, Pei J, Fu X, Wang Z, Hou L, Li N, Wu F and Pan J (2010a). Investigating the surface rupture process of the Wenchuan earthquake $\left(M_{\mathrm{S}} 8.0\right)$. Quaternary $S c i$ ences 30: 677-698 (in Chinese with English abstract).

Li H, Xu Z, Si J, Pei J, Li T, Huang Y and Wang H (2010b). Characteristics of the fault-related rocks, fault zone structures and the principal slip zone of the Wenchuan earthquake in WFSD drilling cores. American Geophysical Union, Fall Annual Meeting. San Francisco, T53E-02, Dec. 13-17, 2010.

Lin A, Ren Z, Jia D and Wu X (2009). Co-seismic thrusting rupture and slip distribution produced by the 2008 $M_{\mathrm{W}} 7.9$ Wenchuan earthquake, China. Tectonophysics 471: 203-215, doi: 10.1016/j.tecto.2009.02.014.

Liu-Zeng J, Zhang Z, Wen L, Tapponnier P, Sun J, Xing X, Hu G, Xu Q, Zeng L, Ding L, Ji C, Hudnut K W and van der Woerd (2009). Co-seismic ruptures of the 12 May 2008, $M_{\mathrm{S}} 8.0$ Wenchuan earthquake, Sichuan: East-west crustal shortening on oblique, parallel thrusts along the 
eastern edge of Tibet. Earth Planet Sci Lett 286: 355370.

Loeblich A R and Tappan H (1964). Treatise on Invertebrate Paleontology, Part C, Protista. Geol. Soc. America \& Univ. Kansas Press.

Marone C (1998). Laboratory-derived friction laws and their application to seismic faulting. Annual Review of Earth and Planetary Sciences 26: 643-696.

Mizoguchi K, Hirose T, Shimamoto $\mathrm{T}$ and Fukuyama E (2007). Reconstruction of seismic faulting by highvelocity friction experiments: An example of the 1995 Kobe earthquake. Geophys Res Lett 34(1): L01308, doi:10.1029/2006GL027931.

Mizoguchi K, Hirose T, Shimamoto T and Fukuyama E (2009). High-velocity frictional behavior and microstructure evolution of fault gouge obtained from Nojima fault, southwest Japan. Tectonophysics 471: 285-296.

Ohnaka M and Yamashita T (1989). A cohesive zone model for dynamic shear faulting based on experimentally inferred constitutive relation and strong motion source parameters. J Geophys Res 94(B4): 4 089-4 104.

Olsen K B, Madariaga R and Archuleta R J (1997). Threedimensional dynamic simulation of the 1992 Landers earthquakes. Science 278: 834-838.

Rauser-Chernoussova D M and Fursenko A V (1962). Fundamentals of paleontology, General Part, Protozoa. Academia Nauka USSR.

Reches Z and Lockner D A (2010). Fault weakening and earthquake instability by powder lubrication. Nature 467: 452-455.

Rempel A W (2006). The effects of flash-weakening and damage on the evolution of fault strength and temperature. Radiated Energy and the Physics of Earthquake Faulting, Geophys Monogr Ser 170: 263-270.

Rempel A W and Weaver S L (2008). A model for flash weakening by asperity melting during highspeed earthquake slip. J Geophys Res 113: B11308, doi:10.1029/2008JB005649.

Rice J R (1999). Flash heating at asperity contacts and ratedependent friction. Eos Trans AGU 80(46): F471.

Rice J R (2006). Heating and weakening of faults during earthquake slip. $J$ Geophys Res 111: B05311, doi:10.1029/2005JB004006.

Rice J R, Sammis C R and Parsons R (2005). Off-fault secondary failure induced by a dynamic slip pulse. Bull Seismol Soc Am 95: 109-134.

Ruina A (1983). Slip instability and state variable friction laws. J Geophys Res 88: 359-370.

Sawai M, Shimamoto T and Togo T (2012). Reduction in BET surface area of Nojima fault gouge with seismic slip and its implication for the fracture energy of earthquakes. J Struct Geol 38: 117-138.

Scholz C H (2002). The Mechanics of Earthquakes and Fault- ing. Cambridge University Press, Cambridge, 471.

Templeton E L and Rice J R (2008). Off-fault plasticity and earthquake rupture dynamics: 1 . Dry materilas or neglect of fluid pressure changes. J Geophys Res 113: B09306, doi:10.1029/2007JB005529.

Tinti E, Spudich P and Cocco M (2005). Earthquake fracture energy inferred from kinematic rupture models on extended faults. J Geophys Res 110: B12303, doi:10.1029/2005JB003644.

Togo T and Shimamoto T (2012). Energy partition for grain crushing in quartz gouge during subseismic to seismic fault motion; an experimental study. J Struct Geol $\mathbf{3 8}$ : 139-155.

Togo T, Shimamoto T, Ma S and Hirose T (2011a). Highvelocity frictional behavior of Longmenshan fault gouge from Hongkou outcrop and its implications for dynamic weakening of fault during 2008 Wenchuan earthquake. Earthquake Science 24: 267-281.

Togo T, Shimamoto T, Ma S, Wen X and He H (2011b). Internal structure of Lonmenshan fault zone at Hongkou outcrop, Sichuan, China, that caused the 2008 Wenchuan earthquake. Earthquake Science 24: 249-265.

Verberne B A, He C and Spiers C J (2010). Frictional properties of sedimentary rocks and natural fault gouge from Longmenshan fault zone, Sichuan, China. Bull Seismol Soc Am 100: 2 767-2 790.

Wells D L and Coppersmith K J (1994). New empirical relationships among magnitude, rupture length, rupture width, rupture area, and surface displacement. Bull Seismol Soc Am 84: 974-1 002.

$\mathrm{Xu} \mathrm{X}$, Wen X, Yu G, Chen G, Klinger Y, Hubbard J and Shaw J (2009). Coseismic reverse-and oblique-slip faulting generated by the $2008 M_{\mathrm{W}} 7.9$ Wenchuan earthquake, China. Geology 37(6): 515-518, doi:10.1130/G25462A.1.

Xu Z, Ji S, Li H, Hou L, Fu X and Cai Z (2008). Uplift of the Longmenshan Range and the Wenchuan earthquake. Episodes 31(3): 291-301.

$\mathrm{Xu} \mathrm{Z}$ and $\mathrm{Li} \mathrm{H}$ (2010). New results from the Wenchuan Earthquake Fault Scientific Drilling Project (WFSD). American Geophysical Union, Fall Annual Meeting. San Francisco, T53E-01, Dec. 13.-17, 2010.

Yang T, Chen J Y, Wang H and Jin H (2012). Rock magnetic properties of fault rocks from the rupture of the 2008 Wenchuan earthquake, China and their implications: preliminary results from the Zhaojiagou outcrop, Beichuan Country (Sichuan). Tectonophysics 530-531: 331-341.

Yao L, Shimamoto T, Ma S, Chen J and Togo T (2011). Internal structures and high-velocity frictional properties of Longmenshan fault zone at Pingxi outcrop, Sichuan, China. AOGS 8th Annual General Meeting. Taipei, Taiwan, Aug. 8-12, 2011. 